concerning ordinary complex quantities, or at least analogous to them." "In fact," he continues, "the arithmetic of hyper-complex quantities can lead to no result which could not be reached by processes known in the theory of ordinary complex quantities."

The views of Dedekind upon this last point quite coincide with those of Weierstrass; but for an account of his beautiful method of generating systems of complex quantities, the reader is for the present referred to the memoirs cited above.

JoHNs Hopkins UnIVERSITY, February 3, 1892.

C. H. Chapman.

\title{
EMILE MATHIEU, HIS LIFE AND WORKS.*
}

IF it were asked what tyranny in this world has least foundation in reason and is at the same time most overbearing and capricious, none could be found to answer better to this description than fastion; that fashion which makes us admire to-day what but yesterday would have excited astonishment, and which may provoke ridicule to-morrow. We all know that this sovereign whose iron rule is so much more keenly felt on account of its injustice governs the thousand and one details of every-day life; that it is supreme in literature and in the arts. But those who have not watched closely the life of the scientific world may perhaps be surprised to hear that even there if you would please you must bend the knee to fashion. What? might exclaim the stranger to the world of science, can it be true that the mathematician knows other laws than the inflexible rules of logic? Does he care to obey other orders than the invariable commands of reason ?-Well, yes. Of course, to have a mathematical production accepted as correct, it is sufficient that it conform to the precepts of logic ; but to have it admired as beautiful, as interesting, as of importance, to gain honor and success by it, more is required : it must then satisfy the manifold and varying exactions imposed by the prevailing taste of the day, by the preferences of prominent men, by the preoccupations of the public.

Thus it comes to pass that, in mathematics as elsewhere, fashion will sometimes award the laurels to those who have not deserved the triumph and make victims of men whose lack of success is an injustice. In every country there are such victors and such victims; but nowhere perhaps are they

\footnotetext{
* Translated from the MS. of the author by Professor ALEXander ZIWET.
} 
more numerous than in France. In this country where centralization is carried to an extreme, nothing is accepted unless it receive the sanction of Paris, or rather of certain constituted bodies, of certain official persons residing in Paris. Those who have been so fortunate as to have their work noticed by these persons and approved by these bodies, who have been granted admission to the chairs of the capital, form in the opinion of the French public the only men of science worthy of honor. The others, relegated to the provinces, are left to oblivion, almost like those seigneurs in the age of Louis XIV. whom a caprice of the monarch relegated to their country estates. Such are the reflections suggested to my mind by the contemplation of the life and works of Emile Mathieu. An indefatigable and productive worker he leaves behind him the results of a lifework, partly as newly acquired possessions of science, partly as suggestions that will open new paths to the seeker after truth. After a life full of disappointments, he died at a time when the official men of science hardly had begun to suspect that somewhere in the provinces, far away from the capital, there lived a mathematician whose works were an honor to his country. These works had one defect: the subjects they treated, the methods they employed, were not in fashion!

Emile Mathieu was born at Metz, on the 15th of May, 1835.* From early youth he showed a taste for study. While attending the lycee at Metz he was year after year awarded, by the consent of his fellow-pupils, the prize for scholarship and conduct. His uncle Aubertin, colonel of artillery and director of the gun foundries at Metz, was there to point him the way to the Ecole Polytechnique. But at this period it was not in mathematics he excelled, but in the study of the classics; the prizes he took again and again in those early years at the lycée were for Latin and Greek compositions. However, his special aptitude for the abstract sciences soon developed. itself. From the time he reached the higher grades at the lycée, he continued to rank first in mathematics. He entered the Polytechnic School at an early age. There he devoted himself exclusively to mathematical studies; and a few months after leaving this institution he resigned his commission in the army to give himself entirely to scientific work. While yet at the Polytechnic School he had published an interesting paper $\uparrow$ in which he extended to finite differences the algebra-

* The biographical data contained in this article are for the most part taken from the Notice sur E'. Mathieu, sa vie et ses travaux, prepared by his colleague G. Floquet for the Bulletin de la Société des sciences de Nancy.

† "Nouveaux théorèmes sur les équations algébriques," in Nouv. Ann. de math., vol. 15 (1856), pp. 409-430. 
jcal theorems of Descartes and Budan regarding derivatives and differentials. This paper proved of some service to Mathieu when he presented himself for the degree of Bachelor of Science, which he had neglected to do before. As Duhamel began examining him in algebra the candidate presented to him a copy of his pamphlet, and the professor after glancing through its pages declared the examination finished.

Scarcely eighteen months had elapsed since this first examination when Mathieu, who had not yet reached the age of twentyfour, took the degree of Doctor of the Mathematical Sciences. On the 28th of March, 1859, he defended before the Sorbonne his thesis On the number of values a function can assume, and on the formation of certain multiply transitive functions. This thesis was very favorably received by the Faculty. The theory of substitutions which formed the subject of this thesis furnished the young mathematician material for two otherimportant papers, * which were published in Liouville's Journal between the years 1859 and 1862. In these papers Mathieu investigates more fully the idea of multiply transitive functions. He studies in particular the various classes of multiply transitive functions whose degree is a power of a prime number or such a power increased by one. In the course of this study he discovered the curious fivefold transitive function of 12 elements. This function and the fourfold transitive function of 11 elements which he also investigated form two entirely isolated cases in the domain of transitive functions as was shown by C. Jordan. $\dagger$

In another memoir, $\$$ published in 1862 in the Annali di Matematica, Mathieu undertakes to apply to the solution of equations whose degree is a power of a prime a resolvent function which stands in the same relation to these equations as does Lagrange's resolvent to the equations whose degree is a prime number. These important researches concerning the most difficult parts of algebra and appearing within so brief a period could not fail to attract the attention of the scientific world to the young mathematician; and this attention soon manifested itself in the most flattering manner. In April, 1862, the Paris Academy of Sciences had to elect a

* "Mémoire sur le nombre de valeurs que peut acquérir une fonction quand on y permute ses variables de toutes les manières possibles," in Liouville's Journ. de math., 2 series, vol. 5 (1860), pp. 9-42 ; and "Mémoire sur l'étude des fonctions de plusieurs quantités, sur la manière de les former ct sur les substitutions qui les laissent invariables," ib., vol. 6(1861), pp. 241-323.

† "Recherches sur les substitutions," in Liouville's Journ., 2 ser., vol. 17 , p. 351 .

$\ddagger$ "Mémoire sur la résolution des équations dont le degré est une puissance d'un nombre premier," in Tortolini's Ann. di mat., vol. 4, pp. 113-132. 
member in the section of geometry. Lame who at the time was dean of the section asked that the name of E. Mathieu be placed on the list of candidates. Nor was Lamé alone with his opinion in the Academy ; Liouville fully approved it. This honor conferred upon a young man of not yet twenty-seven years of age who had not taken any steps to solicit such distinction was indeed a brilliant promise for the future. Who would then have predicted that he who so early received this promise was to die at the age of fifty-five, after a life wholly consecrated to the advance of science without being admitted by the Academy even among the number of its correspondents? Mathieu at that time held no official appointment. While engaged in the profound researches which gained him the favor of Lamé he was compelled to make a living by devoting himself to the exhausting and thankless work of a private tutor. Prouhet who was examiner (répétiteur) at the Polytechnic School procured him employment as assistant, or "quizmaster," in the lycée St. Louis, the lycée Charlemagne, and various private schools. These unremitting labors brought on a serious illness from which he at length recovered thanks to the care of his devoted mother.

In 1863 Mathieu first entered upon the study of mathematical physics. In a note $O n$ the flow of liquids through tubes of very small diameter, published in the Comptes rendus of the Academy of Sciences, * he shows that the adhesion of a very thin layer of liquid to the walls of the tube is sufficient to account for the results of Poiseuille's experiments. A few years later, in 1866, he published an important paper On the dispersion of light. $\uparrow$ In the same year Lamé, whom ill-health prevented from continuing his course at the Sorbonne on mathematical physics and the theory of probability, presented. him as his substitute to Duruy, then minister of public instruction. He was however not appointed as the minister had already made his selection. This chair of mathematical physics at the Sorbonne was to remain for Mathieu the neverattained goal of his ambition. In $186 \%$, at the Congress of the Scientific Societies, a gold medal was awarded him for his fruitful researches. At the same time J. Bertrand published his well-known Report on the progress of mathematical anal$y$ sis. The following passage is found in this report :

"M. E. Mathieu has studied far more fully than had been done before, the idea of transitive functions, first introduced by Cauchy, and his memoir deserves quite special mention,

\footnotetext{
* "Sur le mouvement des liquides dans les tubes de très-petit diamètre," in Comptes rendus, vol. 57 (1863), pp. 320-324.

† "Mémoire sur la dispersion de la lumière," in Liouville's Journ., 2 ser., vol. 11 (1866), pp. 49-102.
} 
on account both of the importance of the new results it contains and of the ingenious form of the proofs. Other memoirs by M. Mathieu, relating to mathematical physics, give evidence, like his algebraical researches, of acute penetration and broad learning. An account of these memoirs will be given in another report, whose author, I trust, will heartily join me in calling attention to a young man who truly possesses the gifts of a mathematician, but has so far, in spite of the estimation in which he is held by all, remained outside the sphere to which his remarkable investigations ought to gain him ready access."

Toward the end of the year 186\%, M. Duruy, influenced no doubt by the high reputation attained by the name of $E$. Mathieu, offered him the complementary course in mathematical physics just then created at the Sorbonne. This was an entrance to public instruction : the young mathematician accepted with eagerness. He published later, in $18 \% \%$, the substance of this complementary coturse in a work to which we shall have to return. This work shows him thoroughly imbued with the teachings of the great masters, Fourier, Laplace, Poisson, Lamé. He proves himself fully conversant with their methods of integration and knows how to use them for the treatment of questions as yet unapproached, such as the difficult problem of the cooling of a planetary ellipsoid. Mathieu had already turned his attention to mathematical physics, having published a memoir on the theory of light, when this appointment determined him to devote his main efforts to the applications of analysis to mechanics and physics. $\mathrm{He}_{\mathrm{c}}$ did not, however, completely abandon the pursuit of puro mathematics. Thus, in $186 \%$, he published an important paper On the theory of biquadratic remainders.* Gauss had found by induction that the biquadratic character of a prime number depends on its decomposition into the sum of two squares; but he did not succeed in discovering the law of this dependence of which he says : "At lex hujus distributionis abstrusior videtur, etiamsi quadam generalia prompte animadvertantur." Mathieu in his memoir actually discovers and proves this law. Later, in 1873, we see him return to the theory of substitutions and investigate the relations of his fourfold transitive function of 11 elements to Kronecker's function of 11 elements. $\nmid$

But these investigations in pure analysis must henceforth be regarded as constituting only an incidental part of Ma-

* "Mémoire sur la théorie des résidus biquadratiques," in Liouville's Journ., 2 ser., vol. 12 (1867), pp. 377-438.

+ "Sur la fonction cinq fois transitive de 24 quantités," in Liouville's Journ., 2 ser., vol. 18 (1873), pp. 25-46. 
thieu's work. Researches in analytical mechanics, in celestial mechanics, in mathematical physics become the constant object of his meditations. In spite of the importance of the results obtained by him in the domain of the theory of substitutions and the theory of numbers, it can therefore be said that what characterizes his scientific individuality is his work in applied mathematics. "Not having found the encouragement I had expected for my researches in pure mathematics, I gradually inclined toward applied mathematics, not for the sake of any gain that I might derive from them, but in the hope that the results of my investigations would more engage the interest of scientific men." In this hope he was deceived. The death of Lamé resulted in finally bringing mathematical physics into discredit in France. D'Alembert, Olairaut, Lagrange, Laplace, Legendre, Fourier, Poisson, Cauchy, Navier. Fresnel, Ampère, Sadi Carnot, Clapeyron, Lamé, accumulated in the course of a century the discoveries that had grown out of the fruitful union of mathematical speculation and the observation of nature. Reactions are abrupt and extreme in the country that had brought forth this succession of men of genius. Suddenly, the path they had laid open was forgotten ; the results of their researches were no more known to their successors; the problems that had occupied their minds were regarded as futile and childish; and while the higher minds took refuge in the realm of mathematical combinations devoid of all reality, the great mass of students turned to the ascertainment of facts, to experimentation without theory, without idea.

It is this forgotten, despised, and scorned tradition of the great mathematical physicists that E. Mathieu had the ambition and the honor to follow, in the face of the indifference of his time. All these great authors he studies with passion, he expounds and compares them, he corrects their errors, he elucidates and complements the most rigorous propositions they had obtained. He is imbued with their spirit; he fully appreciates whatever in their ideas is imperishable, and once in a while, as in the preface to his Course of mathematical physics, he has a smile of pity for those who pretend to despise that with which they are unacquainted. There is one among these masters to whom he has a particular affinity ; it is Poisson,--Poisson who is too fertile in resource, too powerful in genius, to be appreciated at his full value by those, so numerous to-day, who dread long memoirs and difficult analytical processes. Mathieu had studied him thoroughly; he might be said to be his successor. Such tendencies were not calculated to secure Mathieu in the good graces of his contemporaries. His researches might require great intellectual qualities; they might be fraught with beautiful results; 
what of it? He was the champion of a science that was out of fashion.

The complementary course to which he had been appointed did not promise him a very stable position. The future seemed so little assured that when the chair of pure mathematics at Besancon became vacant, Mathieu did not hesitate to apply for it. The scientific men who constituted the Council for the Improvement of the Polytechnic School unanimously recommended him for the position, and he received it without difficulty. Four years later, in 1873, he was trans. ferred in the same capacity to Nancy. From this time on he finds himself relegated to profound and undeserved oblivion. Several times chairs become vacant at the Sorbonne, at the Collège de France; by his memoirs and his books, he is just the man to fill the place; and yet nobody thinks of seriously considering his candidacy. The Academy of Sciences forgets that, somewhere in France, there lives a man who through the whole of his scientific work, through the advance produced by it in physics, is fully entitled to its rewards and honors. And only a few months before his death is he at last allowed to adorn his button-hole with that decoration which is so stingily bestowed upon those who honor their country, and so profusely on those who reap honor and profit from their fatherland.

It had been Poisson's desire to give, in a series of works, a connected view of all that is rigorously known of mathematics as applied to the study of nature; but he had not time to publish more than four volumes of this gigantic undertaking : his Treatise on mechanics, his Theory of heat, and his Theory of capillary action. Mathieu conceived this same idea whose execution, owing to the broad advances made in all branches of mathematical phvsics since Poisson's time had assumed far wider dimensions though, on the other hand, the task had perhaps become more simple and easier to accomplish on account of the comprehensiveness and generality of modern analytical methods. More fortunate than Poisson, he was able to carry the work much farther than his predecessors; but he, too, died before accomplishing his purpose. Eight of the eleven volumes that this work was to comprise have been published. The first of these volumes appeared in 1873 . It bears the title Course of mathematical physics;* but as the author himself remarked later on, it should have been called : On the methods of integration in mathematical physics. It represents the final form of the analytical introduction to the physical sciences that Mathieu had given his students at the Sorbonne in 186\%-1868. In $18 \% 8$ appeared the Analytical

* Cours de physique mathématique. Paris, Gauthier-Villars, 1874. 4to. 
dynamics, * a kind of introduction to celestial mechanics. In 1883, Messrs. Gauthier-Villars published the Theory of capillarity, + in sumptuous typographical execution. This was followed, in 1885-1886, by the two volumes on the Theory of the potential and its applications to electrostatics and magnetism 1 ; in 1888, by a volume on the Theory of electrodynamics $\$$; finally, in 1890 , by two volumes on the Theory of elasticity of solid bodies.

At the time of his death Mathieu was actively engaged on the theory of the elasticity of the ether, that is on optics. We have examined with painstaking care the papers left by the indefatigable worker when the chain of his meditations was broken forever. But the hope of obtaining at least some fragments of the work he had planned was not realized ; the notes we had in our hands did not bear the stamp of the author's genius. We could only trace out from them the general plan of this treatise which was intended to give an exposition of the traditional science of optics as elaborated, after Fresnel, by Green, MacCullagh, Newman, Lamé, and G. Kirchhoff. Within the narrow limits of this article it would be impossible to give a full account of the numerous new results dispersed throughout the memoirs and books published by Mathieu. We shall only try to sketch the general tendencies which mark his character and individuality as distinct from that of the army of mathematical physicists.

Like Poisson and Lamé, Mathieu is skilful in treating particular problems of mathematical physics, in integrating the partial differential equations in certain special cases. Let us here mention for illustration a few of the more difficult among the questions of this nature that he succeded in solving. As early as in 1868 we find him engaged on a problem presenting great difficulties; it is the theory of the oscillatory motions of a homogeneous elliptic membrane subjected to an equal tension in all directions. 9 He succeeded in determining completely the sounds it produces and the shape of its nodal lines. The only cases whose solution was known before this

* Dynamique analytique, Gauthier-Villars, 1878. 4to.

+ Théorie de la capillarité, ib., 1883. 4to.

¥ Théorie du potentiel et ses applications à l'électrostatique ct au magnétisme. Ire partie: Théorie du potentiel, ib., 1885. Ile partie: Electrostatique et magnétisme, ib., 1886. 4to.

$\$$ Théorie de l'électrodynamique, ib., 1888. 4to.

Théorie de l'élasticité des corps solides. Ire partie: Considérations générales sur l'élasticité ; emploi des coordonnées curvilignes; problèmes retalifs à l'équilibre de l'élasticité; plaques vibrantes; ib., 1890. IIe partie: Mouvements vibratoires des corps solides; équilibre de l'élasticité du prisme rectangle; ib., 1890.4 to.

ণ "Mémoire sur le mouvement vibratoire d'une membrane de forme elliptique," in Liouville's Journ., 2 ser., vol. 13 (1868), pp. 137-203. 
are the vibrations of rectangular and triangular membranes whose theory was shown by Lamé to be intimately connected with certain delicate questions in the theory of numbers, and the vibrations of circular membranes whose properties depend on Bessel's functions. In his Course of mathematical physics Mathieu treats another difficult problem which had been pointed out to him by Lamé and which is somewhat allied to the preceding question, viz. the cooling of a planetary ellipsoid. There is a problem to which Lamé attached great importance ; it is the theory of the deformations of a rectangular parallelopipedon whose six faces are subjected to forces distributed in any way whatever. After a long and unsuccessful study of the question he made it repeatedly the subject of one of the prizes of the Academy of Sciences, but without result. Mathieu succeeded in solving, if not the general problem, at least a rather comprehensive special case : the extremities of the prism pressing against two fixed walls and the external force being the same along a generating line of the prism.

We may also mention among the special problems solved by Mathieu the difficult question of the distribution of the electric currents in a rectangular prism or a rectangular lamina. But in spite of the analytical power displayed in the solution of such particular cases, they do not constitute the most important and characteristic part of Mathieu's work, the part that distinguishes his work from that of Fourier, of Poisson, of Cauchy. In the first place it must be said that, while full of respect for the tradition of these men of genius, Mathieu does not allow this reverence to become a superstition; he knows where to depart from their views. In the theory of elasticity he does not hesitate to abandon Poisson's favorite theory of molecular attraction to follow the more rigorous ideas of Lamé. In optics he shows that the calculations by which Cauchy thought to have unfolded the nature of the ether and its relations to ponderable matter lead to inadmissible conclusions; and he boldly modifies the differential equations by which the great master had represented the motion of light in an absorbing medium. In the second place, Mathieu is far more mindful of the generality of the methods he uses than was the custom with the great mathematicians of the beginning of the century. In the very preface to his Course of mathematical physics we see him proclaim his ideas on this point with perfect distinctness: "As the domain of science broadens and expands it becomes more and more necessary to expound its principles with clearness and conciseness and to substitute for artificial processes, however skilful, the transformations that can be accounted for by the nature of the subject. This is clearly illustrated in comparing the Mécanique analytique of Lagrange with the Vorlesungen of 
Jacobi on the same subject. Examining the treatment of certain problems in each of these works the results obtained will often be found to be the same; the difference consists in the fact that in the latter work the calculations are performed according to rules laid down in advance."

The ideas expressed in this passage are everywhere kept in view in Mathieu's treatises. In his Analytical dynamics he introduces at the very beginning the general methods due to Hamilton and Jacobi. In his Theory of capillarity he lays aside the direct consideration of the capiliary forces employed by Poisson, and follows Gauss in establishing the equations for the various problems by seeking to determine the minimum of the potential of the active forces. In the Theory of the elasticity of solid bodies he invariably uses the principle of virtual velocities to throw the problems of equilibrium into equations. This care for generality is also Mathieu's guide in the solution of problems requiring the use of hypotheses that are uncertain or only approximately true. Following a method which in our opinion could not be too much recommended, he always begins by establishing the equations of the problem and treating them as long as possible withont making use of those hypotheses so as to introduce them only at the end. In this way he has treated the motion of a projectile in the air and the equilibrium of rods. General methods have the advantage of bringing into clear perspective the principles that serve to solve the problems, and in this way they will frequently lead one to recognize the possibility of attacking a problem which might seem to escape the treatment by more special processes. Mathieu has thus succeeded in throwing a clear light on certain theories not hitherto approached. We may mention two examples.

The oscillatory motion of a plane lamina had been treated before; but not that of a curved lamina. Without solving the problem of the vibrations of an absolutely general curved plate, Mathieu prepared at least the way for the solution of the general problem, reconnoitring, so to speak, the ground in two important directions, by studying the vibrations of a cylindrical plate of any cross-section, or curved lamina, and those of a plate of revolution, or bell. Let us briefly examine the results of his memoir On the oscillatory motion of bells.* The thickness of ordinary bells is not generally the same throughout. Hence, to obtain a theory applicable to ordinary bells, the thickness must be assumed to vary in passing along any meridian from the top of the bell to the base. There is an essential distinction between the vibratory motion of a bell and that of a plane

* “Mémoire sur le mouvement vibratoire des cloches," in Journ. de l'École Polytechn., Cah. 51, pp. 1'ir-247. 
lamina. In the latter, as is well known, the longitudinal or tangential motion and the transversal or normal motion are given by different equations. In a bell, the normal and tangential vibrations are given by three equations which are not independent of each other. Another distinction from the case of a plane lamina lies in the fact that the pitch of a bell does not change if its thickness be varied throughout in the same ratio, since the terms depending on the square of the thickness in the differential equations are generally very small and may be neglected. This, at least, will be the case if only the deepest sounds produced by the bell are taken into consideration. When a bell vibrates under the strokes of the clapper the tangential vibrations are generally of the same order of magnitude as the normal vibrations. The author has examined whether it be possible to so select the meridian of a bell as to give it a purely tangential vibratory motion; and he has shown that this is only possible in a spherical bell of constant thickness. Although the differential equations of the most general vibratory motion of a spherical bell present themselves under a rather complicated form, Mathieu has succeeded in integrating them by means of formulæ of remarkable simplicity.

In connection with this theory of the vibrations of a bell which Mathieu owes to the generality of his methods we may mention another result which, though of a more special nature, deserves to remain classic on account of its intrinsic importance as well as of the elegance of the demonstration. This is the complete determination of the action produced by the capillary forces on a solid body partly immersed in a liquid. Poisson had only succeeded, by very complicated though skilful processes, in determining the vertical upward pressure produced on a solid of revolution whose axis is vertical.

But we must now speak of what is perhaps the most noteworthy part of Mathieu's work. Most problems of mathematical physics depend not only on one or more partial differential equations but also on so-called boundary conditions adapted to determine the arbitrary functions introduced by the integration of the equations. This science requires therefore the investigation of partial differential equations, not taken by themselves, but in connection with such boundary conditions and taking into account the form of any such conditions that may be given. This method has proved a remarkably fruitful source of beautiful results in analysis. It will be sufficient to mention the theory of the potential and the numerous theories connected with the principle of Dirichlet. If investigations of this kind have for some time been neglected by pure mathematicians, they have always called forth 
the efforts of the physicists. Poisson, Helmholtz, Kirchhoff have accumulated the results in the study of the equations that occur in the theories of sound and light. They have thus prepared the way for the resumption of those researches which, owing to the labors of H. A. Schwarz and E. Picard, are at the present day again coming into general favor. And in the work of maintaining this now triumphant tradition only gross injustice could refuse to recognize the important part taken by E. Mathieu. He has devoted a large number of memoirs to researches of this nature concerning the equations of sound, of elasticity, and of heat.

As early as in 1868, in his memoir on the vibrations of an elliptic membrane, he indicates or foresees a part of the results established later on by $\mathrm{H}$. A. Schwarz and E. Picard in their beautiful researches on the equation

$$
\frac{\delta^{2} u}{\delta x^{2}}+\frac{\delta^{2} u}{\delta y^{2}}+p u=0
$$

At a later period he rediscovers and systematizes the results obtained by Helmholtz in studying the equation

$$
\Delta u+k^{2} u=0 \text {. }
$$

Similar considerations he extends to the equation

$$
\Delta u=k \frac{\delta u}{\delta t} \text {. }
$$

But his most noteworthy researches in this field are those on the partial differential equation of the fourth order

$$
\Delta \Delta u=0 \text {, }
$$

which governs the components of the pressures and the components of the displacements at the interior of an isotropic body in the state of elastic equilibrium.* Designating as first potential the function usually denoted simply as potential, the author considers under the name of second potential another analytical expression differing from the former in having the distance of two points substituted for the inverse of the distance; and he develops the entirely new theory of this second potential. Concerning the partial differential equation of the fourth order which expresses the equilibrium of elasticity he proves the following theorem : Every function that satisfies this equation at the interior of a surface and is there continuous itself as well as its derivatives of the first three orders is

* "Mémoire sur l'équation aux différences partielles du quatrième ordre $\Delta \Delta u=0$, et sur l'équilibre d'élasticité d'un corps solide," in Liouville's Journ., 2 ser., vol. 14 (1869), pp. 378-421. 
the sum of the first potential of a layer covering the bounding surface and of the second potential of another layer spread over the same surface.

I here conclude this exposition of Mathieu's work, not for want of material, for I have said nothing of his researches in the theory of perturbations and regarding the problem of three bodies, but in order not to exceed the limits of this article. Besides, whoever desires to obtain accurate information on the state in which his predecessors had left the science of mathematical physics and on the advances made in it by himself can do better than read me by reading $\mathrm{him}$. I have known E. Mathieu only as a man of science; and I have spoken of him only as such. To describe the man I must borrow the testimony of one of those who have best known him, one of his colleagues at the Faculty of Sciences of Nancy*: "Of an essentially straightforward, sincere, and generous nature, he was kindness itself. He possessed the devotion that seeks to be ignored. In July, 1890, when the fatal disease had already attacked him, he succeeded in concealing his ill-health from his colleagues, being unwilling to leave to them the burden of his examinations. In September, on his deathbed the same anxiety agitated his mind with respect to the October examinations. His loyal and trustworthy character made him esteemed and beloved by all ; in the Faculty at Nancy he had none but friends. Sensitive to any kindness, touched by the slightest mark of sympathy, he belonged to those who are most easily satisfied. He lived in simple style dividing his time between his lectures and his mathematical researches."

P. DUHEM,

Lecturer in Mathematical Physics and Crystallography at the Faculty of Sciences of Lille.

* G. Floquet, loc. cit. 